\title{
Ethionamide, prothionamide and thiacetazone self-administration. Studies of patient compliance using isoniazid-marked formulations
}

\author{
J N A STANLEY,* J M H PEARSON* \\ \& G A ELLARD †† \\ * Dhoolpet Leprosy Research Centre, Hyderabad 500 006, Andra \\ Pradesh, India; $\dagger$ National Institute for Medical Research, London \\ NW7 1AA, England
}

Accepted for publication 4 November 1985

\begin{abstract}
Summary The acceptability of ethionamide, prothionamide and thiacetazone as potential companion drugs for the treatment of lepromatous leprosy was assessed in two small scale studies carried out among out-patients in Hyderabad. Specially formulated tablets or capsules containing $6 \mathrm{mg}$ isoniazid as an innocuous marker were prescribed and their ingestion demonstrated by collecting urine samples at surprise home visits and testing for the presence of isoniazid metabolites by a simple colorimetric procedure. About three-quarters of the prescribed thioamide doses were ingested and daily doses of $125 \mathrm{mg}$ ethionamide, and 125 or $250 \mathrm{mg}$ prothionamide were of similar acceptability to the patients. Furthermore, prothionamide and dapsone could be given together in a single daily capsule without compromising the dapsone compliance of the patients. However more extensive studies of thioamide compliance are required before these drugs can be confidently recommended for the treatment of lepromatous patients unable to tolerate clofazimine. Thiacetazone compliance was poorer supporting the conclusion that thiacetazone should not be recommended for the treatment of leprosy.
\end{abstract}

\section{Introduction}

The thioamide drugs ethionamide and prothionamide are recommended for the treatment of patients with lepromatous leprosy who are unable to tolerate clofazimine. The suggested regimen is $250-375 \mathrm{mg}$ thioamide self-administered daily for at least 2 years with daily self-administered dapsone and monthly supervised rifampicin. ${ }^{1}$ The success of this treatment may well be determined by the regularity with which patients take thioamides; thus information is required

$\ddagger$ Reprint requests to G A Ellard. 
on their acceptability before they can be unreservedly advised for use in leprosy control programmes.

Experimental studies in the mouse foot-pad ${ }^{2-4}$ and investigations of their pharmacokinetics in $\operatorname{man}^{5-7}$ indicate that ethionamide and prothionamide have similar clinical potencies. Experimental studies have also demonstrated that when ethionamide was administered once a week its bactericidal activity was abolished and leprosy bacilli multiplied between doses. ${ }^{8}$ Under typical out-patient conditions many leprosy patients take dapsone very irregularly and intermissions in treatment of 4 days or more are common; ${ }^{9}$ the therapeutic activity of the thioamides would probably be compromised were they taken with this degree of irregularity.

The thioamides have been widely used in the past for the treatment of pulmonary tuberculosis but nowadays are little used. Gastro-intestinal sideeffects were common, though prothionamide appeared to be somewhat better tolerated. ${ }^{10}$ However, the dosage used (500-1000 mg daily) was higher than is advised for the treatment of leprosy. Little is known of the acceptability and sideeffects of the thioamides in lower dosages, although recent reports of their hepatotoxicity when combined with rifampicin are causing concern. ${ }^{11}$

Thiacetazone is not recommended for use in the treatment of leprosy ${ }^{1}$ primarily because it is a rather weak bacteriostatic drug ${ }^{12}$ whose efficacy is likely to be seriously compromised by poor compliance. Recent studies indicate that thiacetazone concentrations capable of inhibiting the multiplication of Mycobacterium leprae would only be maintained for about 3 days in the event of patients discontinuing to take their thiacetazone treatment. ${ }^{13}$ Nevertheless in view of its cheapness, there are still those who advocate its use especially in those parts of the world where previous experience in the mass treatment of tuberculosis has suggested thiacetazone is reasonably well tolerated.

In previous studies we have established the feasibility of using special formulations of antileprosy drugs containing $6 \mathrm{mg}$ of isoniazid as an innocuous marker in investigations of patient compliance. ${ }^{14,15}$ Ingestion of the marker is revealed by a simple colorimetric urine test for the isoniazid metabolites isonicotinic acid and isonicotinylglycine. This paper describes the use of these isoniazid-marked formulations to investigate the regularity with which outpatients in Hyderabad ingested ethionamide, prothionamide and thiacetazone when prescribed with dapsone for daily self-administration.

\section{Methods}

TREATMENT OF PATIENTS AND COLLECTION OF URINE SAMPLES

The general procedures followed were as employed in the previous investigation of dapsone compliance by patients in Hyderabad. ${ }^{15}$ Twenty-one male and 9 female patients participated in the 2 studies, including 22 who had taken part in the former dapsone investigation. Their ages ranged from 15 to 74 years (mean 40 
years), they weighed from 27 to $68 \mathrm{~kg}$ (mean $48 \mathrm{~kg}$ ); and had previously been treated for up to 17 years (mean 5 years). Monthly supplies of their allocated medication were issued when the patients attended the clinic for their regular monthly medical check-up and they were encouraged to swallow their prescribed daily treatment first thing each morning. Urine samples were collected by means of surprise home visits approximately once every fortnight. A randomized home visiting schedule was devised for this purpose so that the paramedical worker usually came on a different day of the week in order to ensure that the patients would not be able to guess when the next visit might be due. Ninety-five per cent of the samples were collected between 9 am and 12 noon that is some 3-6 hours after the daily doses of drugs should have been ingested.

\section{THIACETAZONE STUDY}

The objective of this study was to assess the regularity of thiacetazone and dapsone self-administration when they were prescribed either as a combined capsule or as separate thiacetazone capsules and dapsone tablets for daily treatment. There was an initial 'run-in' period of 6 weeks on standard dapsone tablets (100 mg daily). During this period 18 patients were treated on 3 consecutive days with a capsule containing dapsone $100 \mathrm{mg}$ plus isoniazid $6 \mathrm{mg}$ in place of the standard dapsone tablets. Urine samples were collected during this period by daily home visits, and each patient's 'compliant dapsone/creatinine $(\mathrm{D} / \mathrm{C})$ ratio' determined in order to increase the precision with which their subsequent dapsone compliance could be interpreted. ${ }^{15}$

After the run-in period, patients were assigned to two consecutive 12 week daily treatment schedules:

(a) One capsule: thiacetazone $150 \mathrm{mg}+$ isoniazid $6 \mathrm{mg}$ and one standard $100 \mathrm{mg}$ dapsone tablet.

(b) One capsule: thiacetazone $150 \mathrm{mg}+$ isoniazid $6 \mathrm{mg}+$ dapsone $100 \mathrm{mg}$.

Nine patients were assigned by random allocation to receive treatment (a) followed by treatment (b), the rest were given these treatments in the reverse order.

\section{THIOAMIDE STUDY}

The objective of this study was to compare the regularity of ethionamide and prothionamide self-administration when they were prescribed at doses of $125 \mathrm{mg}$ or $250 \mathrm{mg}$ for daily treatment with dapsone. During the first 36 weeks of the 48 week study, 12 patients were assigned to 3 consecutive 12-week daily thioamide plus dapsone treatment schedules:

(a) One tablet: ethionamide $125 \mathrm{mg}$ + isoniazid $6 \mathrm{mg}$ and one standard $100 \mathrm{mg}$ dapsone tablet.

(b) One tablet: prothionamide $125 \mathrm{mg}+$ isoniazid $6 \mathrm{mg}$ and one standard $100 \mathrm{mg}$ dapsone tablet.

(c) One capsule: prothionamide $250 \mathrm{mg}+$ isoniazid $6 \mathrm{mg}+$ dapsone $100 \mathrm{mg}$. 
Two patients were assigned by random allocation to each of the 6 possible sequences in which the regimens could be administered (abc, acb, bac, bca, cab and cba). At the end of the 36 weeks, the 4 patients on capsules continued with the same treatment for the remaining 12 weeks while the other patients who were receiving ethionamide or prothionamide tablets were treated with 2 thioamide tablets ( $250 \mathrm{mg}$ ethionamide or prothionamide plus $12 \mathrm{mg}$ isoniazid) plus $100 \mathrm{mg}$ dapsone each day.

\section{ANAL YTICAL PROCEDURES}

Aliquots of urine were preserved with a crystal of thymol at $0-4^{\circ} \mathrm{C}$ until shipment by air (without ref rigeration) to London for subsequent analysis. $\mathrm{D} / \mathrm{C}$ ratios were estimated by determining the urinary concentrations of dapsone plus its diazotisable metabolites (as dapsone equivalents) and creatinine by modifications of the Bratton and Marshall and alkaline picrate procedures, respectively. ${ }^{16}$ Urine samples were tested for the presence of isonicotinic acid and isonicotinyl glycine as described previously. ${ }^{15}$ Among urine samples from smokers, a positive result was indicated by the formation of grey or brown colours $30 \mathrm{~min}$ after reaction; negative samples gave orange or pink colours. ${ }^{17}$ Among non-smokers, positive samples gave blue or green colours, while a negative result was indicated by a straw or yellow colour or by no apparent colour formation. Negative results implied that a $6 \mathrm{mg}$ marker dose of isoniazid had not been ingested during the previous $18 \mathrm{~h} .{ }^{14}$ In order to supplement the qualitative results, concentrations of isonicotinic acid plus isonicotinylglycine (as 'apparent' isonicotinic acid) were estimated by measuring the optical density of the reacted samples at $600 \mathrm{~nm}$ and apparent isonicotinic acid/creatinine $(\mathrm{I} / \mathrm{C})$ ratios calculated. ${ }^{14}$

\section{Results}

COMPARISON OF QUALITATIVE AND QUANTITATIVE METHODS

Among the 463 urine samples with creatinine concentrations greater than $0 \cdot 1 \mathrm{mg} /$ $\mathrm{ml}$, there was an excellent agreement between the qualitative and quantitative assessments of the presence of isonicotinic acid and isonicotinylglycine in the urine. Thus the $\mathrm{I} / \mathrm{C}$ ratios of the 185 samples read as negative by eye $(40 \%$ of the total) averaged $0.41 \mu \mathrm{g} / \mathrm{mg}$ in contrast with a mean ratio of 2.35 for the 278 samples that were judged by eye to be positive. Similarly only 7 of the 185 samples read as negative had $\mathrm{I} / \mathrm{C}$ ratios of greater than 0.75 , while only 8 of the 278 positive samples had ratios of less than this value. The concordance between the qualitative and quantitative findings among the 73 samples with creatinine concentrations of $0 \cdot 1 \mathrm{mg} / \mathrm{ml}$ or less was however much poorer. Thus 64 of the 66 samples that were judged by eye to be negative had $\mathrm{I} / \mathrm{C}$ ratios of greater than 0.75 (mean 2.77). It was therefore concluded that the simple qualitative procedure was unreliable under conditions of extreme diuresis. The results presented in this 
Table 1. Thiacetazone study. Proportions of negative isonicotinic acid urine tests.

\begin{tabular}{lcc}
\hline \multicolumn{1}{c}{ Prescribed treatment } & Proportion negative & Percentage negative \\
\hline Separate thiacetazone capsules and dapsone tablets & $33 / 77$ & 43 \\
Combined thiacetazone and dapsone capsules & $23 / 64$ & 36 \\
\hline All & $56 / 141$ & 40 \\
\hline
\end{tabular}

paper are therefore restricted to the findings obtained on urine samples with creatinine concentrations greater than $0 \cdot 1 \mathrm{mg} / \mathrm{ml}$.

\section{THIACETAZONE STUDY}

The results are presented of the analyses of the urine samples collected from 16 of the 18 patients originally admitted to the study. One patient was withdrawn from the study after developing ischaemic heart disease during the run-in phase prior to starting thiacetazone treatment and another left the city to find work elsewhere.

\section{Thiacetazone compliance}

Overall compliance was unsatisfactory. Whether thiacetazone was administered as combined capsules with dapsone, or separately plus dapsone tablets, about $40 \%$ of the urine samples collected gave negative isonicotinic acid urine tests, indicating the omission of at least 1 thiacetazone dose (Table 1). There were marked differences in individual compliance among the 16 patients, the compliance of 3 was excellent (not a single negative isonicotinic acid urine test), while the drug taking of 5 was poor and accounted for about $60 \%$ of all the missed doses in the study.

Actual drug ingestion often failed to correspond with the apparent acceptability of the prescribed thiacetazone treatment. Thus 2 of 3 patients who complained of side-effects attributable to thiacetazone (giddiness, nausea, loss of appetite, weakness, abdominal pain or paraesthesia) continued to take their treatment regularly, while the compliance of 4 patients without a single complaint was poor.

\section{Dapsone compliance during thiacetazone administration}

The regularity with which the dapsone doses were taken was estimated by comparing the $\mathrm{D} / \mathrm{C}$ ratios of the samples with the patients' 'mean compliant' $\mathrm{D} / \mathrm{C}$ ratios. The latter were calculated from the $\mathrm{D} / \mathrm{C}$ ratios of samples giving positive isonicotinic acid urine tests when they were prescribed isoniazid-marked dapsone-containing capsules. ${ }^{15}$

The results obtained indicated the number of dapsone doses that were likely to have been ingested during the 4 days prior to the collection of each urine sample. The cumulative percentages of missed dapsone doses for each patient during the 
Table 2. Thiacetazone study. Estimated percentages of missed dapsone doses.

\begin{tabular}{lccc}
\hline \multicolumn{1}{c}{ Prescribed treatment } & \multicolumn{3}{c}{ Percentages of missed dapsone doses } \\
& None & $<20$ & $>20$ \\
\hline Dapsone monotherapy (run-in period) & 6 & 3 & 5 \\
\hline $\begin{array}{l}\text { Separate thiacetazone capsules and dapsone tablets } \\
\text { Combined thiacetazone/dapsone capsules }\end{array}$ & 2 & 4 & 8 \\
\hline
\end{tabular}

three treatment periods were then calculated (Table 2). The results presented are for only 14 patients, since urine samples were not obtained from 2 of the patients during the dapsone monotherapy run-in phase. Although there was a suggestion that the inclusion of thiacetazone might have discouraged the self-administration of dapsone, the percentages of missed dapsone doses during the thiree treatment periods did not differ significantly $(P>0 \cdot 1)$.

\section{THIOAMIDE STUDY}

The results are presented of the analysis of urine samples collected from 11 patients; the twelfth patient died of burns sustained in a domestic fire early in the study.

\section{Thioamide compliance}

During the initial 36 weeks of the study about a quarter of the patients had failed to take their prescribed thioamide dose earlier in the morning of the surprise home visit (Table 3). Very similar proportions of $125 \mathrm{mg}$ tablets of ethionamide or prothionamide were ingested by the patients. Although there was a suggestion that the combined prothionamide $(250 \mathrm{mg}) /$ dapsone capsules might have been taken more regularly than either the $125 \mathrm{mg}$ ethionamide or the $125 \mathrm{mg}$ prothionamide tablets, the differences between the proportions of negative urine test were not significant $(P>0.25$ and $>0 \cdot 1$ respectively). Prescribing a final 12 weeks daily treatment with two $125 \mathrm{mg}$ tablets of ethionamide (to 4 patients) or prothionamide (to 3 patients) did not change the percentages of negative

Table 3. Thioamide study. Proportions of negative isonicotinic acid urine tests.

\begin{tabular}{lcc}
\hline \multicolumn{1}{c}{ Prescribed treatment } & Proportion negative & Percentage negative \\
\hline Ethionamide tablets $(125 \mathrm{mg})$ & $15 / 52$ & 29 \\
Prothionamide tablets $(125 \mathrm{mg})$ & $19 / 57$ & 33 \\
Prothionamide capsules $(250 \mathrm{mg})$ & $9 / 51$ & 18 \\
\hline All & $43 / 160$ & 27 \\
\hline
\end{tabular}


isonicotinic acid urine tests significantly compared with the previous 12-week period when they had been given a single tablet a day $(48 \%$ vs $47 \%$ for ethionamide, $17 \%$ vs $23 \%$ for prothionamide). However the calculated $\mathrm{I} / \mathrm{C}$ ratios, which should have doubled if 2 isoniazid-marked tablets were ingested each day, revealed that among the 5 supposedly compliant patients, only 3 were regularly taking 2 thioamide tablets each day.

The compliance of the 11 patients varied enormously. Thus over $90 \%$ of the urine samples collected from 3 of the patients gave positive isonicotinic acid tests. By contrast half of the urine samples from 3 other patients were negative and accounted for about $70 \%$ of all the missed thioamide doses in the study. Compliance approximately paralleled acceptability; of the 6 patients who had no complaints about taking the thioamides, 5 took their medication reasonably regularly.

\section{Thioamide toxicity}

One patient developed a facial itch and another diarrhoea which they attributed to prothionamide and as a consequence refused to continue thioamide treatment. The symptoms however subsequently responded to treatment for tinea barbae and taeniasis plus amoebiasis, respectively.

Two patients developed nausea, vomiting, salivation and indigestion almost certainly due to thioamides. Both were given symptomatic treatment and encouraged to continue to take their thioamide. Both claimed to be continuing treatment, but one stopped ingesting prothionamide while continuing to take her dapsone regularly.

Two of the patients developed jaundice (after 30 and 34 weeks of thioamide treatment, respectively). Both were chronic alcoholics. Drugs were stopped immediately and the patients made uneventful recoveries. Thioamides were not restarted.

\section{Dapsone compliance during thioamide administration}

The estimated percentages of dapsone doses missed by the 11 patients during the first 36 weeks of the study are shown in Table 4. Although there was a suggestion that combining dapsone with prothionamide in a single capsule might actually have encouraged the ingestion of dapsone, the percentages of missed dapsone doses in the two treatment schedules did not differ significantly $(0 \cdot 05<P<0 \cdot 1)$.

Table 4. Thioamide study. Estimated percentages of missed dapsone doses.

\begin{tabular}{lccc}
\hline \multicolumn{1}{c}{ Prescribed treatment } & \multicolumn{3}{c}{ Percentages of missed dapsone doses } \\
& None & $<20$ & $>20$ \\
\hline Separate thioamide and dapsone tablets & 2 & 6 & 3 \\
Combined prothionamide/dapsone capsules & 7 & 2 & 2 \\
\hline
\end{tabular}


There was considerable variation between individuals in their compliance; 3 were excellent, 6 average and 2 poor by the criteria used in the previous study. ${ }^{15}$ The last 2 patients accounted for two-thirds of all the missed dapsone doses in the entire study and also ingested their prescribed thioamides very irregularly. When the remaining 9 patients were prescribed combined prothionamide plus dapsone capsules, the 40 urine samples tested revealed only 3 single lapses in compliance, suggesting that they would have responded very favourably to thioamidecontaining treatment regimens.

\section{Discussion}

\section{Thiacetazone compliance}

Throughout much of Africa and the Indian subcontinent thiacetazone rarely appears to give rise to important adverse side-effects. ${ }^{18}$ In these areas it has been widely used in the treatment of pulmonary tuberculosis and is generally regarded as a well tolerated drug. However the absence of complaints on obvious sideeffects does not necessarily imply that compliance is good. Thus urine samples were tested from lepromatous patients in Ethiopia whose daily dapsone treatment had been supplemented with daily thiacetazone (as 'Thiazina' tablets containing $150 \mathrm{mg}$ thiacetazone plus $300 \mathrm{mg}$ isoniazid) in an attempt to prevent the emergence of dapsone-resistant leprosy. Some two-thirds of the samples gave negative isonicotinic acid results indicating that the patient had failed to swallow a dose of thiacetazone within the previous $48 \mathrm{~h} .{ }^{19}$ Not surprisingly the thiacetazone supplement failed to reduce the rate at which the patients relapsed with dapsone-resistant leprosy. ${ }^{20}$

Although the thiacetazone compliance of the patients in Hyderabad was much better than in Ethiopia, with about $60 \%$ of the prescribed doses being ingested, it was still probably inadequate. Thus when thiacetazone was given in a combined capsule with dapsone, the estimates of numbers of missed dapsone doses indicated that in 3 of the 16 patients intermissions of at least 3 days had occurred.

In the current study, as in the previous Ethiopian one, there was frequent contact and apparently good rapport between the staff and patients. Nevertheless, in both investigations thiacetazone was shown to be irregularly ingested despite the avowed absence of side-effects in many of the patients. It would seem that the ill-effects of thiacetazone are subtle enough to defy easy description yet sufficient to discourage self-medication. Whatever the reason, both studies indicate that thiacetazone compliance is unlikely to reach the levels required for it to be a therapeutically effective component for the treatment of lepromatous leprosy.

\section{Thioamide compliance}

In view of the small number of patients studied and the marked variations in individual patient compliance, great caution must be exercised in the interpreta- 
tion of the findings. However, the cross-over design employed allows us to conclude with reasonable confidence that $125 \mathrm{mg}$ doses of ethionamide and 125 $\mathrm{mg}$ and $250 \mathrm{mg}$ doses of prothionamide were of similar acceptability to the patients and that a combined formulation of dapsone plus prothionamide could be prescribed without prejudicing dapsone compliance. Overall about threequarters of the prescribed thioamide doses appeared to have been ingested and in only 3 patients was compliance unsatisfactory. This may be regarded as an initially encouraging finding.

A major factor influencing the potential contribution of the thioamides to the treatment of lepromatous leprosy is their propensity to cause hepatic damage, especially when given in combination with rifampicin. ${ }^{11}$ Two of the 12 patients treated with thioamides in the current study developed jaundice. Although the liver damage was predominantly attributed to alcohol, thioamide treatment was immediately terminated and will not be restarted.

Thus among the 12 patients prescribed thioamides in the current study, thioamide treatment was discontinued in 2 patients because of potential hepatic toxicity and the compliance of 2 others was inadequate. We therefore conclude that it will only be possible to recommend ethionamide or prothionamide for the general treatment of lepromatous patients unable to tolerate clofazimine after more extensive investigations of their compliance and hepatic toxicity have been undertaken.

\section{Acknowledgments}

We wish to thank the International Dispensary Association, Amsterdam, The Netherlands, for the gift of isoniazid-marked capsules and May and Baker, Dagenham, Essex, England for the isoniazid-tagged ethionamide and prothionamide tablets. The home visits were undertaken by Mr Syed Yousuff Jani, Mrs Deveena Prabhaker and Mr Daniel Jones. J M H Pearson is a member of the staff of Victoria Hospital, Dichpalli, on secondment from the National Institute for Medical Research, London. Dhoolpet Leprosy Research Centre is managed by Victoria Hospital, Dichpalli, in collaboration with the Medical Research Council (of Great Britain), and also receives support from the British Leprosy Relief Association.

\section{References}

1 WHO Study Group. Chemotherapy of leprosy for control programmes. WHO, Technical Report Series, 1982; No. 675.

2 Colston MJ, Ellard GA, Gammon PT. Drugs for combined therapy: Experimental studies on the antileprosy activity of ethionamide and prothionamide, and a general review. Le pr Rev, 1978; 49: $115-26$.

${ }^{3}$ Colston MJ, Hilson GRF, Banerjee DK. The 'Proportional bactericidal test'. A method for assessing the bactericidal activity of drugs against M. leprae in mice. Lepr Rev, 1978; 49: 7-15. 
${ }^{4}$ Shepard CC, Jenner PJ, Ellard GA, Lancaster RD. An experimental study of the antileprosy activity of a series of thioamides in the mouse. Int $J$ Lepr, 1985; 53: In press.

5 Jenner PJ, Ellard GA. High-performance liquid chromatographic determination of ethionamide and prothionamide in body fluids. $J$ Chromatogr, 1981; 225: 245-51.

6 Jenner PJ, Ellard GA, Gruer PJK, Aber VR. A comparison of the blood levels and urinary excretion of ethionamide and prothionamide in man. J Antimicrob Chemother, 1984; 13: 26777.

7 Jenner PJ, Smith SE. Plasma levels of ethionamide and prothionamide in man following intravenous and oral dosages. In preparation.

${ }^{8}$ Colston MJ, Hilson GRF, Lancaster RD. Intermittent chemotherapy of experimental leprosy in mice. Am J Trop Med Hyg, 1980; 29: 103-8.

9 Ellard GA. Drug compliance in the treatment of leprosy. Lepr Rev, 1981; 52: 210-13.

${ }^{10}$ Fox W, Robinson DK, Tall R, Mitchison DA, Kent PW, Macfadyen DM. A study of the intolerance to ethionamide, including a comparison with prothionamide, and of the influence of a vitamin B-complex additive in prophylaxis. Tubercle, 1969; 50: 125-43.

11 Ji Baohong, Chen Jiakun, Wang Chenmin, Xia Guang. Hepatotoxicity of combined therapy with rif ampicin and daily prothionamide for leprosy. Lepr Rev, 1984; 55: 283-9.

12 Colston MJ, Hilson GRF, Ellard GA, Gammon PT, Rees RJW. The activity of thiacetazone, thiambutosine, thiocarlide and sulphamethoxypyridazine against M. leprae in mice. Lepr Rev, 1978; 49: 101-13.

13 Jenner PJ, Ellard GA, Swai OB. A study of thiacetazone blood levels and urinary excretion in man, using high performance liquid chromatography. Lepr Rev, 1984; 55: 121-8.

14 Ellard GA, Jenner PJ, Downs PA. An evaluation of the potential use of isonazid, acetylisoniazid and isonicotinic acid for monitoring the self-administration of drugs. Br J Clin Pharmac, 1980; 10: $369-81$.

15 Stanley JNA, Pearson JMH, Ellard GA. An investigation of dapsone compliance using an isoniazid-marked formulation. Lepr Rev, 1983; 54: 317-25.

${ }^{16}$ Ellard GA, Gammon PT, Helmy HS, Rees RJW. Urine tests to monitor the self-administration of dapsone by leprosy patients. Amer J Trop Med Hyg, 1974; 23: 464-70.

17 Peach H, Ellard GA, Jenner PJ, Morris RW. A simple, inexpensive urine test of smoking. Thorax, 1985; 40: 351-7.

18 Miller AB, Nunn AJ, Robinson DK, Fox W, Somasundaram PR, Tall R. A second international cooperative investigation into thiacetazone side effects. Bull Wld Hlth Org, 1972; 37: 211-27.

19 Ellard GA, Pearson JMH, Haile GS. The self-administration of dapsone by leprosy patients in Ethiopia. Lepr Rev, 1981; 52: 237-43.

${ }^{20}$ Warndorff van Diepen T, Mengistu G. Relapse rate and incidence of dapsone resistance in lepromatous leprosy patients in Addis Ababa: risk factors and effect of short-term supplementary treatment. Int J Lepr, 1985; 53: 189-97. 